\title{
How is Systemic Blood Pressure and Intraocular Pressure Related?
}

\author{
Sunil Deokule \\ Department of Ophthalmology and Visual Sciences, University of Kentucky, Lexington, KY, USA
}

Population based studies have shown that ocular intraocular pressure (IOP) is a major and only realistic modifiable risk factor for glaucoma. ${ }^{1,2}$ Therefore, it is important to study the characteristics that are associated with raised IOP. Several factors are associated with raised IOP, i.e. age, gender, central corneal thickness, race, blood pressure, body mass index, lens status, etc. ${ }^{3-6}$ There is increasing evidence that systemic blood pressure (BP) is related with IOP, however reported associations between BP and IOP in healthy individuals and OAG patients are contradictory. This review summarizes the relationship between BP and IOP in a healthy subject and in an OAG patient.

\section{ASSOCIATION OF SYSTOLIC BLOOD PRESSURE (SBP) AND IOP}

SBP was positively associated with IOP in the Barbados Eye Study, which excluded subjects with OAG from analysis. ${ }^{3}$ The 4-year and 9-year follow-up data from the Barbados Incidence Study of Eye Diseases I and II (BISED I and BISED II), which examined the surviving cohort of the Barbados Eye Study, demonstrated a trend of increase in IOP with increasing SBP. ${ }^{4,7}$ Similarly positive correlation between SBP and IOP was evident in the Baltimore Longitudinal Study of Aging (BLSA) and 2 large Japanese studies that included normal subjects. ${ }^{8-10}$

In addition to a positive correlation in normal individuals, several studies have consistently demonstrated a positive correlation between BP and IOP, in populations that include patients with OAG (Table 1). In general, each $10 \mathrm{~mm} \mathrm{Hg}$ increment in SBP at baseline leads to mean 0.23-0.31 mm Hg rise in IOP. ${ }^{5,10-13}$ Similarly the Beaver Dam Study shows that an increase of SBP by $\geq 10 \mathrm{~mm} \mathrm{Hg}$ from baseline leads to $0.44 \mathrm{~mm}$ $\mathrm{Hg}$ rise in IOP whereas a decrease of SBP by $\leq 10 \mathrm{~mm} \mathrm{Hg}$ from baseline leads to $0.59 \mathrm{~mm} \mathrm{Hg}$ decrease in IOP, over a 5-year interval. ${ }^{14}$

The positive correlation between SBP and IOP is observed across all races in both healthy individuals and OAG patients.
The Rotterdam Study, the Egna-Neumarkt Study and the Beaver Dam Study were each conducted on populations predominantly of European descent. However, the Barbados Eye Study that had predominantly African ancestry participants, the Baltimore Eye Survey in which almost one half of the patients were of African ancestry, and the Tanjong Pagar Study that was conducted on entirely Asian population, all confirm a strong correlation between SBP and IOP, as well. ${ }^{5,10,12}$ A recent report from Los Angeles Latino Eye Study (LALES) confirmed higher systolic blood pressure as one of the two major factor associated with elevated IOP in the Latino population (patients with glaucoma were excluded), other being higher CCT. ${ }^{15}$ A 20 mm Hg higher SBP was associated with $0.7 \mathrm{~mm}$ Hg higher IOP. Further, higher mean blood pressure was significantly correlated with higher IOP in a study of 2597 Japanese adults without glaucoma. Each mm Hg increase in BP was associated with increase in IOP by 0.022 $\mathrm{mm} \mathrm{Hg}{ }^{16}$

\section{ASSOCIATION OF DIASTOLIC BLOOD PRESSURE (DBP) AND IOP}

The evidence for a positive relationship between DBP and IOP is contradictory. DBP was associated with a marginally significant rise of $0.15 \mathrm{~mm} \mathrm{Hg}$ in IOP over 9 years follow-up in BISED II. ${ }^{7}$ In LALES higher DBP was associated with elevated IOP, however the association was not as strong as between SBP and elevated IOP. ${ }^{15} \mathrm{DBP}$ contributed to $2 \%$ of IOP variance compared to $4 \%$ contribution by SBP, on univariate analysis. On multivariate analysis the correlation between SBP and IOP continued to be strong whereas the correlation between DBP and IOP weakened to $0.09 \%$ contribution of DBP to IOP variance. In contrast; BLSA and the Japanese studies demonstrated no apparent correlation between DBP and IOP. ${ }^{8-10}$

Similar to SBP, DBP is positively correlated with IOP in patients with OAG; each $10 \mathrm{~mm} \mathrm{Hg}$ increment in DBP at baseline leads to 0.19-0.6 mm Hg rise in IOP (Table 1). ${ }^{5,10-12,17}$ Over a 
Table 1: Summary of major studies demonstrating a relationship between BP and IOP

\begin{tabular}{|c|c|c|c|c|c|}
\hline Study & $\begin{array}{l}\text { Type of study/study } \\
\text { population }(N)\end{array}$ & $\begin{array}{l}\text { Increase in IOP } \\
\text { (baseline)/10 } \mathrm{mm} \mathrm{Hg} \\
\text { increase in SBP } \\
\text { ( } \mathrm{mm} \mathrm{Hg}[95 \% \mathrm{CI}] \text { ) }\end{array}$ & $\begin{array}{l}\text { Increase in IOP } \\
\text { (baseline)/10 mm } \mathrm{Hg} \\
\text { increase in DBP } \\
(\mathrm{mm} \mathrm{Hg}[95 \% \mathrm{CI}])\end{array}$ & $\begin{array}{l}\text { Longitudinal rise in } \\
\text { IOP/10 } \mathrm{mm} \mathrm{Hg} \\
\text { increase in SBP } \\
\text { ( } \mathrm{mm} \mathrm{Hg}[95 \% \mathrm{CI}] \text { ) }\end{array}$ & $\begin{array}{l}\text { Longitudinal rise in } \\
\text { IOP/10 } \mathrm{mm} \mathrm{Hg} \\
\text { increase in } \mathrm{DBP} \\
\text { ( } \mathrm{mm} \mathrm{Hg}[95 \% \mathrm{CI}] \text { ) }\end{array}$ \\
\hline Dielemans et $\mathrm{al}^{11}$ & $\begin{array}{l}\text { CSS, Mixed } \\
(4187,55 \text { OAG) }\end{array}$ & $0.23[0.19-0.27]$ & $0.24[0.16-0.32]$ & & \\
\hline Tielsch et $\mathrm{al}^{12}$ & $\begin{array}{l}\text { Prevalence } \\
\text { Survey, Mixed } \\
(5147,161 \text { OAG) }\end{array}$ & 0.25 & 0.19 & & \\
\hline Bonomi et al $^{13}$ & $\begin{array}{l}\text { CSS, Mixed } \\
(4297,60 \text { OAG, } \\
89 \text { OH, } 24 \text { NTG) }\end{array}$ & 0.24 & 0.4 & & \\
\hline LALES $^{15 *}$ & $\begin{array}{l}\text { CSS, Normal } \\
(5,958)\end{array}$ & 0.7 & 0.9 & & \\
\hline Klein et $\mathrm{al}^{5}$ & $\begin{array}{l}\text { CSS, Mixed } \\
\text { (4881) }\end{array}$ & $0.32[0.27-0.37]$ & $0.55[0.46-0.67]$ & & \\
\hline Klein et $\mathrm{al}^{5}$ & $\begin{array}{l}\text { LPCS, Mixed } \\
(4881)\end{array}$ & - & - & $0.21[0.16-0.27]$ & $0.43[0.35-0.52]$ \\
\hline Wu et $\mathrm{al}^{3}$ & $\begin{array}{l}\text { LPCS, normal } \\
(2298)\end{array}$ & - & - & 0.22 & 0.17 \\
\hline
\end{tabular}

* LALES: Los Angeles Latino Eye Study, increase in IOP is for $20 \mathrm{~mm}$ Hg increase in SBP.

CSS $=$ Cross-sectional study, LPCS $=$ Longitudinal population based cohort study.

5-year interval, there was a mean increase of $0.06 \mathrm{~mm} \mathrm{Hg}$ in IOP for subjects with DBP within $10 \mathrm{~mm} \mathrm{Hg}$ of their baseline DBP compared to an increase of $0.85 \mathrm{~mm}$ Hg for those whose DBP increased by $\geq 10 \mathrm{~mm} \mathrm{Hg}$ and a decrease of $0.79 \mathrm{~mm} \mathrm{Hg}$ in IOP for those whose DBP decreased by $\geq 10 \mathrm{~mm} \mathrm{Hg} .^{5}$ There is no satisfactory explanation for the difference in the results between patients with glaucoma and normal subjects. This difference could be due to the gender and racial differences amongst studies.

The pathopysiologic basis for the relationship between BP and IOP is not known. It has been proposed that the positive correlation between SBP and IOP is related to increased BP leading to increased aqueous humor ultrafiltration by means of increased ciliary artery pressure, and thus an increase of IOP. ${ }^{6}$ Conversely roles for common physiologic factors such as generalized sympathetic tone or serum corticosteroids also have been proposed. ${ }^{17}$

\section{CORRELATION BETWEEN BP AND OAG}

Despite having positive correlation, the magnitude of change in IOP with change in BP is quite small $(0.2-0.4 \mathrm{~mm} \mathrm{Hg} / 10 \mathrm{~mm}$ Hg). ${ }^{5,11,12,17-19}$ Further, the correlation between the increase in $\mathrm{BP}$ and development of OAG is weak. The odds ratio (OR) for development of OAG with each $10 \mathrm{~mm} \mathrm{Hg}$ increase in SBP ranges from 1.08 to 1.12 (Table 2). The corresponding OR for the development of OAG for each $10 \mathrm{~mm} \mathrm{Hg}$ increase in DBP is even weaker, and ranges from 1.00 to 1.09 .

However, it has been proposed that there is a threshold effect of SBP on OAG prevalence. ${ }^{11,12}$ The prevalence of OAG increased significantly with higher quartiles of SBP compared to lower quartiles in the Rotterdam Study (Fig. 1). ${ }^{11}$ Similarly, the risk of OAG was higher in subjects with $\mathrm{SBP} \geq 130 \mathrm{~mm} \mathrm{Hg}$ (OR 1.27; $\mathrm{p}=0.17$ ) compared to those who had lower SBP, in the Baltimore Eye Survey. ${ }^{5}$ Recently it was reported in the Rotterdam Study that the OR for OAG was 1.87 (95\% CI, 0.9-3.9) for subjects with SBP of $>145 \mathrm{~mm}$ Hg compared to subjects with lower SBP. ${ }^{17}$ On the contrary, prevalence of OAG increased linearly by $9 \%$ for each $10 \mathrm{~mm} \mathrm{Hg}$ increase in SBP (OR 1.09) and DBP (OR 1.09), which was of borderline significance, in the Blue Mountain Study. ${ }^{20}$

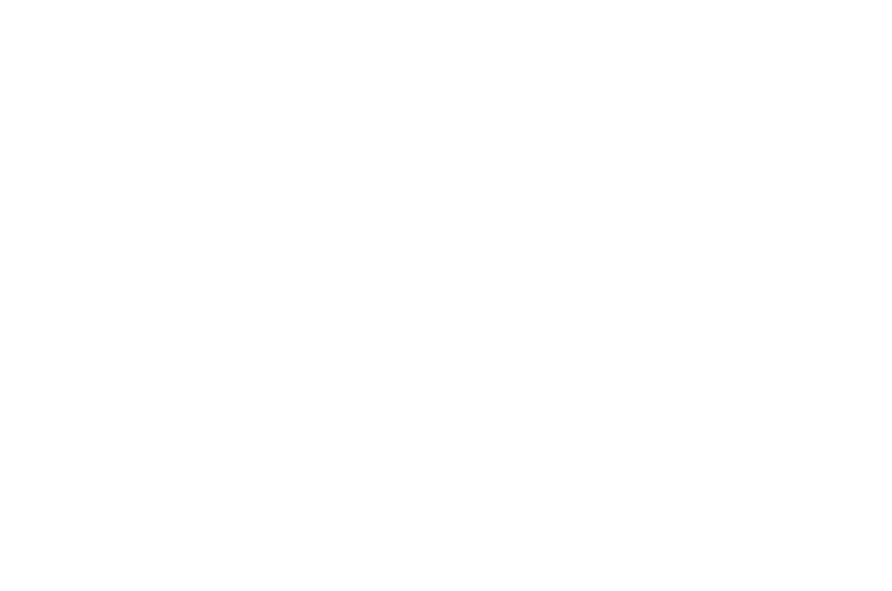

Fig. 1: Prevalence of open angle glaucoma and systolic blood pressure (Tielsch J et al. Arch Ophthalmol 1995:113;216-21) ${ }^{12}$ 
Table 2: Odds ratio for associations between systolic blood pressure (SBP) and diastolic blood pressure (DBP) with open angle glaucoma (OAG), normal tension glaucoma (NTG) and ocular hypertension (OH)

\begin{tabular}{|c|c|c|c|c|c|c|}
\hline Study & $\begin{array}{c}\text { OAG } \\
\text { OR }(95 \% \text { CI) }\end{array}$ & $\begin{array}{c}\text { SBP } \\
\text { NTG } \\
\text { OR }(95 \% C I)\end{array}$ & $\begin{array}{c}\mathrm{OH} \\
\text { OR }(95 \% \quad C I)\end{array}$ & $\begin{array}{c}\text { OAG } \\
\text { OR }(95 \% \text { CI) }\end{array}$ & $\begin{array}{c}\text { DBP } \\
\text { NTG } \\
\text { OR }(95 \% C I)\end{array}$ & $\begin{array}{c}\mathrm{OH} \\
\text { OR }(95 \% \text { CI) }\end{array}$ \\
\hline Dielemans et $\mathrm{al}^{* 11}$ & $1.08(0.94-1.24)$ & $0.90(0.72-1.13)$ & - & $1.00(0.76-1.31)$ & $0.95(0.62-1.44)$ & - \\
\hline Hulsman et ala ${ }^{17}$ & $1.12(0.98-1.29)$ & $1.07(0.91-1.26)$ & - & $1.09(0.96-1.25)$ & $1.18(1.01-1.37)$ & - \\
\hline Mitchell et al $* 20$ & $1.09(1.00-1.18)$ & - & $1.20(1.12-1.28)$ & $1.09(0.90-1.33)$ & - & $1.38(1.20-1.58)$ \\
\hline
\end{tabular}

Table 3: Systolic blood pressure $(\mathrm{mm} \mathrm{Hg})$ and RR for open angle glaucoma ${ }^{21}$

\begin{tabular}{ll}
\hline SBP quartiles & $R R(95 \% \mathrm{CI})$ \\
\hline $\mathrm{SBP}<119$ & 1.0 \\
$119 \leq \mathrm{SBP}<132$ & $0.81(0.38-1.72)$ \\
$132 \leq \mathrm{SBP}<148$ & $0.63(0.29-1.38)$ \\
$\mathrm{SBP} \leq 148$ & $0.51(0.23-1.12)$ \\
\hline SBP $=$ Systolic blood pressure, RR = Relative risk
\end{tabular}

BP may be more strongly correlated with ocular hypertension $(\mathrm{OH})$ than OAG. Each $10 \mathrm{~mm}$ Hg increase in SBP (OR 1.20) and DBP (OR 1.38) was associated with a $20-30 \%$ increase in the prevalence of $\mathrm{OH} .{ }^{19}$ It is notable that increasing BP had either no effect or a protective effect on NTG with the OR either below 1 or with a large confidence interval. ${ }^{11,17}$

The small correlation between higher SBP and IOP and increasing OAG prevalence evident in cross-sectional population studies is not supported by the results from longitudinal population-based cohort studies. Although higher SBP at baseline and a longitudinal increase in SBP from baseline during 4-year follow-up period was associated with higher IOP, the risk of development of OAG tended to decrease as SBP increased (Table 3). ${ }^{21}$ Similarly the 9 -year follow-up data from BISED II study demonstrates that a $9 \%$ decrease in risk of OAG was associated with a $10 \mathrm{~mm} \mathrm{Hg}$ increase in SBP. ${ }^{22}$ Recently, the early manifest glaucoma trial has reported lower SBP at baseline as a predictor for glaucomatous progression, particularly in patients with baseline IOP $<21 \mathrm{~mm} \mathrm{Hg}$. The subjects with baseline SBP > $160 \mathrm{~mm}$ Hg were less likely to progress compared to subjects with SBP $\leq 160 \mathrm{~mm}$ Hg (Hazard Ratio [HR], 0.46 [0.21-1.02]). ${ }^{23}$ This finding, however, was not confirmed by the Canadian Glaucoma Study. ${ }^{19}$ Neither SBP nor DBP at baseline was associated with progression in this study population. It is evident that the relationship between systolic BP and OAG is complex. Though higher BP is associated with higher IOP levels, it is lower BP that may be deleterious to the optic nerve suggesting a role of vascular factors independent of IOP in OAG.

\section{CORRELATION BETWEEN NOCTURNAL BP AND OAG}

Flammer et al have opined that hypotension and, in particular, a nocturnal drop in BP may be more important in OAG then high BP. ${ }^{24}$ Greater prevalence of low BP and of nocturnal overdipping has been reported in OAG and NTG patients. ${ }^{25-31} \mathrm{~A}$ long-term study of 70 glaucoma subjects by Graham et al demonstrated larger nocturnal blood pressure dips in subjects with progressive glaucomatous damage compared to stable glaucoma. ${ }^{29}$ The strongest association was between the magnitude of systolic dip and visual field progression. Subjects were classified as dippers or nondippers, based on criteria of both SBP and DBP falling by $>10 \mathrm{~mm} \mathrm{Hg}$ nocturnally. There were greater numbers of dippers among the patients with progressive field defects $(\mathrm{P}=0.01)$. Interestingly the proportion of dippers and nondippers was similar in NTG and high tension OAG.

The evidence stated above suggests that nocturnal drops in BP may have a role in the pathogenesis of glaucoma, possibly by reducing the $\mathrm{ONH}$ blood flow. Ghergel et al found that glaucoma patients with a marked nocturnal BP drop had altered retrobulbar flow parameters. ${ }^{30}$ Tokunaga et al examined the relation between the nocturnal BP dip and progression of visual field defects in NTG and high tension OAG over a period of 4 years. ${ }^{31}$ Subjects were classified based on the percentage of BP dip nocturnally: < $10 \%$ as nondippers, $10-20 \%$ as physiologic dippers, $>20 \%$ extreme dippers. The progression was evident in both the extreme dipper and the nondipper groups thus suggesting an underlying vascular dysregulation, and not merely low nocturnal BP, as a contributory factor for glaucomatous damage. Perhaps nocturnal BP should be investigated in greater depth as a risk factor for OAG.

\section{SUMMARY}

There is a strong positive association between SBP and IOP, and a weaker association between DBP and IOP. This association is present across the racial lines. However, the actual change in IOP with increasing BP is relatively small. The crosssectional studies suggest a marginal increase in OAG prevalence 
with increasing BP. Incorporation of nocturnal BP measurement in glaucoma management needs further study.

\section{REFERENCES}

1. The Advanced Glaucoma Intervention Study (AGIS): 7 The relationship between control of intraocular pressure and visual field deterioration. The AGIS Investigators. Am J Ophthalmol 2000;130:429-40.

2. Comparison of glaucomatous progression between untreated patients with normal-tension glaucoma and patients with therapeutically reduced intraocular pressures. Collaborative NormalTension Glaucoma Study Group. Am J Ophthalmol 1998;126:48797.

3. Wu S-Y, Leske CM. Associations with intraocular pressure in the Barbados Eye Study. Arch Ophthalmol 1997;115:1572-76.

4. Hennis A, Wu S-Y, Nemesure B. et al. Hypertension, diabetes and longitudinal changes in intraocular pressure. Ophthalmology 2003;110:908-14.

5. Klein BK, Klein R, Knudtson MD. Intraocular pressure and systemic blood pressure: longitudinal perspective: the Beaver Dam Eye Study. Br J Ophthalmol 2005;89:284-87.

6. Bulpitt CJ, Hodes C, Everitt MG. Intraocular pressure and systemic blood pressure in the elderly. Br J Ophthalmol 1975;59:717-20.

7. Wu S-Y, Nemesure B, Hennis A, Leske C, et al. Nine-Year changes in intraocular pressure: the Barbados Eye Studies. Arch Ophthalmol 2006;124:1631-36.

8. McLeod S, West S, Quigley H, Fozard J. A longitudinal study of the relationship between intraocular and blood pressure. Invest Ophthalmol Vis Sci 1990;30:2361-66.

9. Nomura H, Shimokata H, Ando F, Miyake Y, et al. Age-related changes in intraocular pressure in a large Japanese population: A cross-sectional and longitudinal study. Ophthalmology 1999;106: 2016-22.

10. Nalano T, Tatemichi M, Miura Y, Sugita M, et al. Long-term physiologic changes of intraocular pressure: A 10-year longitudinal analysis in young and middle aged Japanese men. Ophthalmology 2005;112:609-16.

11. Dielemans I, Vingerling JR, Algra D, et al. Primary Open angle glaucoma, intraocular pressure and systemic blood pressure in the general elderly population. The Rotterdam Study. Ophthalmology 1995;102:54-60.

12. Tielsch J, Katz J, Sommer A, et al. Hypertension, perfusion pressure and primary open angle glaucoma. A population based assessment. Arch Ophthalmol 1995;113:216-21.

13. Bonomi L, Marchini G, Marraffa M, et al. Vascular risk factors for primary open angle glaucoma. The Egna-Neumarkt Study. Ophthalmology 2000;107:1287-93.

14. Yip J, Aung T, Wong T-Y, et al. Socioeconomic status, systolic blood pressure and intraocular pressure: the Tanjong Pagar Study. Br J Ophthalmol 2007;91:56-61.

15. Associations with intraocular pressure in Latinos: The Los Angeles Latino Eye Study. The Los Angeles Latino Eye Study Group. Am J Ophthalmol 2008;146:69-76.

16. Kawase K, Tomidokoro A, Araie M, et al. Ocular and systemic factors related to intraocular pressure in Japanese adults: The Tajimi Study. Br J Ophthalmol 2008;92:1175-79.
17. Hulsman CA, Vingerling JR, Hofman A, et al. Blood pressure, arterial stiffness and open angle glaucoma. The Rotterdam Study. Arch Ophthalmol 2007;125:805-12.

18. Carel RS, Korczyn AD, Rock M, et al. Association between ocular pressure and certain health parameters. Ophthalmology 1984;91: 311-14.

19. Chauhan BC, Mikelberg FS, Balazi G, LeBlanc RP, et al. Canadian Glaucoma Study: 2. Risk factors for the progression of open angle glaucoma. Arch ophthalmol 2008;126(8):1030-36.

20. Mitchell P, Lee AJ, Rochtchina E, et al. Open angle glaucoma and systemic hypertension. The Blue Mountains Eye Study. J Glaucoma 2004;13:319-26.

21. Leske CM, Wu S-Y, Nemesure B, et al. Incident open angle glaucoma and blood pressure. Arch Ophthalmol 2002;120:954-59.

22. Leske M, Wu S-Y, Hennnis A, Honkanen R, et al. Risk factors for incident open-angle glaucoma: The Barbados Eye Studies. Ophthalmology 2008(Jan);115(1):85-93.

23. Leske CM, Heijl A, Hyman L, et al. Predictors of long-term progression in the early manifest glaucoma trial. Ophthalmology 2007 Nov;114(11):1965-72.

24. Pache M, Flammer J. A sick eye in a sick body? Systemic findings in patients with primary open-angle glaucoma. Surv Ophthalmol 2006;51:179-212.

25. Hayreh SS, Zimmerman MB, Podhasky P, et al. Nocturnal arterial hypotension and its role in optic nerve head and ocular ischemic disorders. Am J Ophthalmol 1994;117:603-24.

26. Bechetoille A, Bresson-Dumont H. Diurnal and nocturnal blood pressure drops in patients with focal ischemic glaucoma. Graefes Arch Clin Exp Ophthalmol 1994;232:675-79.

27. Graham SL, Drance SM, Wijsman K, et al. Ambulatory blood pressure monitoring in glaucoma. The nocturnal dip. Ophthalmology 1995; 102:61-69.

28. Meyer J, Brandi-Dohrn J, Funk J. Twenty-four hour blood pressure monitoring in normal tension glaucoma. $\mathrm{Br} \mathrm{J}$ Ophthalmol 1996;80:864-67.

29. Graham S, Drance S. Nocturnal hypotension: role in glaucoma progression. Surv Ophthalmol 1999;43(Suppl-1):S10-S16.

30. Ghergel D, OrgüL S, Gugleta K, et al. Retrobulbar blood flow in Glaucoma patients with nocturnal over-dipping in systemic blood pressure. Am J Ophthalmol 2001;132:641-47.

31. Tokunaga T, Kashiwagi K, Tsumura T, et al. Association between nocturnal blood pressure reduction and progression of visual field defect in patients with primary open angle glaucoma or normal tension glaucoma. Jpn J Ophthalmol 2004;48:380-85.

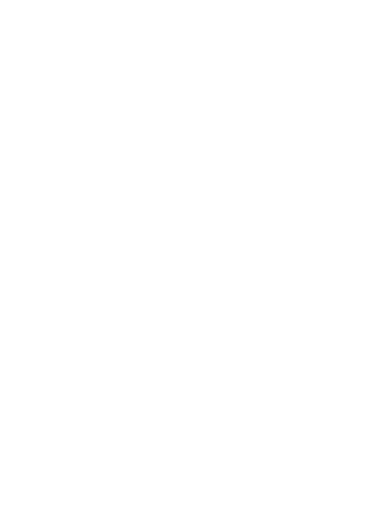

“There are no impossible dreams, just our limited perception of what is possible." 